\title{
ANALISIS FAKTOR-FAKTOR YANG MEMPENGARUHI BAURAN PEMASARAN PADA KEPUTUSAN PEMBELIAN HANDPHOND ANDROID
}

\author{
Didi Zainuddin
}

\author{
Program Studi Teknik Industri, FTMIPA \\ Universitas Indraprasta PGRI \\ Email: didiza.gadept@gmail.com \\ HP: 081585867773
}

\begin{abstract}
The objective of this research is to investigate the effect of brand experience on Brand Relationship Quality on Brand Loyalty, and the influence of Brand Loyalty to Word of Mouth. 169 samples were collected from the respondents. After excluding samples containing missing data, we used 110 samples. In the final sample of 110 respondents, $65.5 \%$ were male, and $52.7 \%$ were between 21 and 23 years old. Data analysis in this study using Structural Equation Model (SEM) to test independent variables that affect the dependent variable. And to measure the validity of research variables using SPSS software version 17.0 The results of this study conclude that the influence of Brand Experience positively and significantly to Word of Mouth mediated by Brand Relationship Quality and Brand Loyalty.
\end{abstract}

Keywords: Brand Experience, Word of Mouth, Brand Relationship Quality, Brand Loyalty

\begin{abstract}
ABSTRAK
Tujuan dari penelitian ini adalah untuk mengetahui pengaruh pengalaman merek terhadap Brand Relationship Quality terhadap Brand Loyalty, dan pengaruh Brand Loyalty terhadap Word of Mouth.169 sampel dikumpulkan dari responden. Setelah mengecualikan sampel yang berisi data yang hilang, kami menggunakan 110 sampel. Pada sampel akhir dari 110 responden, 65,5\% adalah laki-laki, dan $52,7 \%$ berusia antara 21 dan 23 tahun. Analisis data dalam penelitian ini menggunakan Structural Equation Model (SEM) untuk menguji variabel bebas yang mempengaruhi variabel dependen. Dan untuk mengukur validitas variabel penelitian menggunakan software SPSS versi 17.0 Hasil penelitian ini menyimpulkan bahwa pengaruh Brand Experience secara positif dan signifikan terhadap Word of Mouth dimediasi oleh Brand Relationship Quality dan Brand Loyalty.
\end{abstract}

Kata kunci: Brand Experience, Word of Mouth, Brand Relationship Quality, Brand Loyalty 


\section{PENDAHULUAN}

Word of mouth sebagai suatu hal yang dibicarakan oleh banyak orang. Word of mouth merupakan salah suatu strategi yang digunakan oleh marketer dalam menjalankan kegiatan promosinya, selain bentuk promosi yang lainnya seperti iklan, publikasi dan sebagainya. Berbeda dengan bentuk komunikasi marketing pada umumnya, strategi dengan word of mouth lebih besar dalam mencapai target. Hal ini dikarenakan word of mouth diterjemahkan dan dikemas dalam bentuk simbol sebelum disampaikan melalui saluran komunikasi ke penerima pesan, sehingga informasi yang disampaikan langsung diterima target yang pada umumnya adalah orang-orang yang membutuhkan informasi tersebut. Penyebaran informasi dari seorang pelanggan ke pelanggan lain membuat handphone Android pun berkembang pesat. Untuk mewujudkan word of mouth dari seorang pelanggan harus menemukan orang yang tepat sebagai media yang akan menyampaikan pesan, di sisi lain ada alasan bagi mereka untuk menyampaikan pesan dari perusahaan atau produk tertentu, contohnya jika seorang pelanggan yang menggunakan handphone Android akan terlihat lebih memiliki gaya hidup (lifestyle) atau pelanggan terlihat cerdas (smart). Kedatangan sistem Operasi Android di Indonesia memang masih terasa baru, namun saat ini para pengguna Android pun terus bertambah dan semakin ramai, terutama pada pasar teknologi handphone pintar.

Perasaan loyal dari dalam diri pelanggan terhadap handphone Android disebabkan oleh adanya pengembangan kecanggihan teknologi pada handphone pintar sehingga fokus pada pengembangkan konektivitas internet, multimedia, hingga fitur-fitur seperti Global Positioning System (GPS) dan kamera. Fiturfitur lengkap dan harga yang bervariasi dari ponsel pintar inilah yang menjadi incaran pelanggan yang semakin memberikan manfaat dan keuntungan bagi pelanggan. Loyalitas merek ditandai oleh adanya suatu kedalaman komitmen untuk tetap membeli kembali suatu jasa yang dilakukan oleh konsumen (Youl-Ha, John, Janda, dan Muthaly, 2011).

Merk handphone Android menawarkan rasa kesenangan pada organ sensorik, kenyamanan dan keindahan untuk memenuhi perasaan dekat secara emosional pelanggan terhadap handphone Android. Hal ini lebih berkaitan dengan gaya hidup konsumen untuk lebih percaya diri, nyaman, dan bergaya dengan menggunakan merek yang baik. Pelanggan yang berkomitmen memiliki keterikatan emosional terhadap merek atau perusahaan yang ditujunya. Pada umumnya pelanggan mengekspresikan kedalaman komitmen atau perasaan loyal mereka dengan kepercayaan dan kesukaan terhadap merek tersebut serta kepercayaan terhadap perusahaannya. Konsumen yang berkomitmen tidak ingin mencari informasi tambahan pada saat membuat keputusan pembelian. Mereka juga tidak mudah untuk berpindah ke merek pesaing. Meskipun mereka membeli merek pesaing, tetapi setelah penawaran promosi berakhir, seperti diskon, mereka akan kembali ke merek semula. Perpindahan sementara tersebut hanya bersifat memanfaatkan keuntungan yang ditawarkan oleh merek lain. Loyalitas merek juga mampu untuk mencari pelanggan baru yang akan membeli produk atau jasa yang dijual oleh perusahaan (Moisescu dan Allen, 2010).

Adanya cara yang dilakukan oleh perusahaan yang menjual handphone Android berusaha untuk tetap mempertahankan loyalitas merek yaitu dengan menciptakan kepercayaan dan komitmen yang dimiliki oleh pelanggan (Lee dan Kang, 2012). Kepercayaan yang dimiliki oleh konsumen timbul karena perusahaan jujur dan memenuhi apa yang dijanjikan dalam menjual suatu merek produk atau jasa (Louis dan Lombart, 2010).

Kekuatan hubungan yang dimiliki oleh konsumen dianggap sebagai faktor penting dalam menciptakan kualitas hubungan yang baik antara konsumen dengan penyedia jasa (Xie dan Heung, 2009). Kekuatan hubungan ditentukan Komitmen yang dimiliki oleh konsumen timbul karena adanya identifikasi yang dilakukan secara terus-menerus dan adanya kedekatan terhadap penyedia jasa (Fullerton, 2005).

Adapun kepercayaan yang dimiliki oleh konsumen dalam membeli suatu merek produk atau jasa ditentukan oleh adanya pengalaman secara afektif terhadap suatu merek produk atau jasa yang dijual oleh perusahaan (Lee dan Kang, 2012). Pengalaman secara afektif yang dimiliki oleh konsumen dalam jangka panjang dapat menimbulkan kesan positif yang muncul di benak pemikiran konsumen (Joy dan Sherry, 2003). 
Zarantonello dan Schmitt (2010) menyebutkan adanya dimensi yang membentuk Brand Experience adalah :

1. Dimensi sensory adalah dimensi visual, dorongan untuk menggunakan suatu merek produk atau jasa.

2. Dimensi affective adalah perasaan dan kedekatan emosional yang timbul ketika menggunakan merek produk atau jasa.

3. Dimensi Intellectual adalah kemampuan dari suatu pelanggan untuk menjalin hubungan dengan merek produk atau jasa karena seorang pelanggan memiliki pemikiran yang berbeda dengan pelanggan lainnya.

4. Dimensi Behavioural adalah adanya pengalaman, gaya hidup, dan interaksi pelanggan terhadap merek produk atau jasa.

\section{METODE}

Penelitian ini bersifat uji hipotesis (Hypotheses Testing). Data ini merupakan data Cross Sectional, yaitu data yang dikumpulkan pada satu waktu tertentu pada beberapa objek dengan tujuan menggambarkan keadaan Masyarakat yang menggunakan handphone Android (Hermawan, 2006). Variabel yang diteliti adalah Brand Experience, Brand Relationship Quality, Brand Loyalty, dan Word of Mouth.

Brand Experience diukur menggunakan Skala Likert lima point. Brand Experience terbentuk dari lima pernyataan yang diungkapkan oleh Lee dan Kang (2012)

Brand Relationship Quality diukur menggunakan Skala Likert lima point. Brand Relationship Quality terbentuk dari enam pernyataan yang diungkapkan oleh Lee dan Kang (2012).
Brand Loyalty diukur menggunakan Skala Likert lima point. Brand Loyalty terbentuk dari tiga pernyataan yang diungkapkan oleh Lee dan Kang (2012)

Untuk mengetahui apakah semua item pertanyaan item dalam variable tersebut valid maka. Pengujian validitas dilakukan dengan mencari korelasi dari setiap indikator terhadap skor totalnya dengan menggunakan rumus teknik Pearson Correlation Product Moment dengan bantuan software SPSS versi 17.0 (Sekaran, 2006). Keputusan yang diambil dengan cara membandingkan nilai $p$-value dari setiap variabel pernyataan

Dan metode analisis data yang digunakan dengan melihat tujuan penelitian adalah sebagai berikut:

1. Untuk menganalisis pengaruh Brand Experience terhadap Brand Relationship Quality.

2. Untuk menganalisis pengaruh Brand Relationship Quality terhadap Brand Loyalty.

3. Untuk menganalisis pengaruh Brand Loyalty terhadap Word of Mouth. Metode analisis data yang digunakan adalah teknik analisis AMOS (Analyses of Moment Structures) Versi 7 dengan melihat pembentukan Structural Equation Model (SEM).

Untuk menguji kesesuaian model (Goodness of Fit Model) yang ditunjukkan pada SEM (Structural Equation Model). Sebelum menganalisis hipotesis penelitian yang diajukan, terlebih dahulu dilakukan pengujian kesesuaian model (goodness of fit model). Pengujian kesesuaian model (goodness of fit model) dilakukan dengan melihat beberapa kriteria pengukuran. Uraian masing-masing dari goodness of fit index.

\section{Kerangka Konseptual}

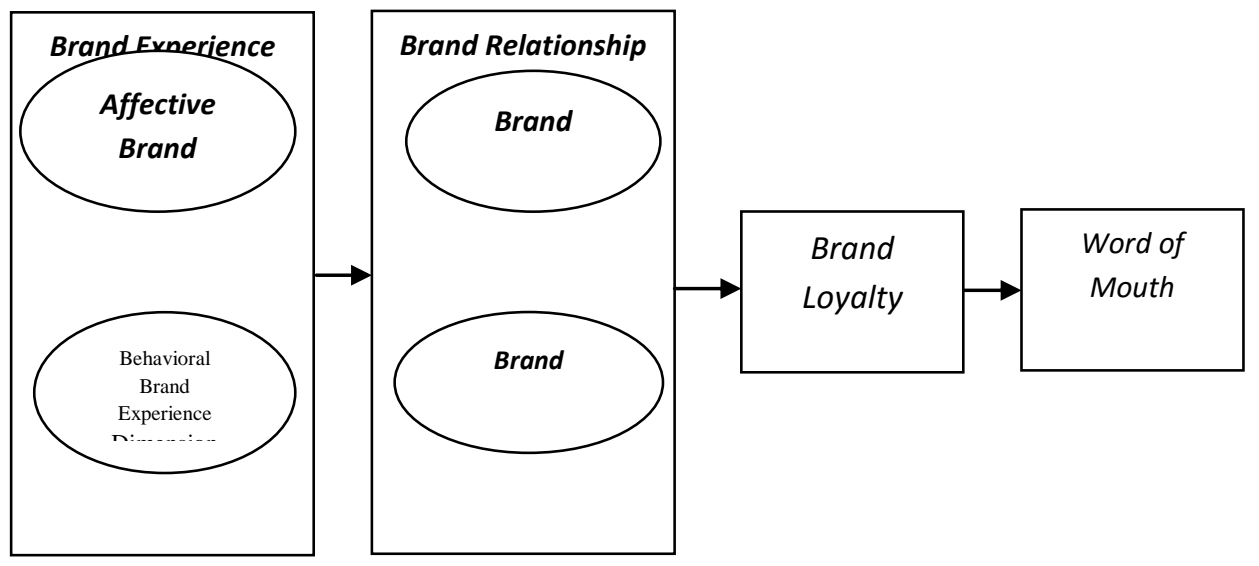




\section{HASIL DAN PEMBAHASAN}

Pada penelitian ini, data yang digunakan adalah data primer. Teknik pengumpulan data yang digunakan adalah purposive sampling. Purposive sampling adalah teknik pengumpulan data berdasarkan kriteria-kriteria tertentu (Hermawan, 2006). Dalam penelitian ini cara penentuan jumlah sampelnya adalah menggunakan rumus Slovin. Adapun profil dari masyarakat yang menggunakan handphone Android sebagai responden ditunjukkan sebagai berikut:

\section{Karakteristik Demografis Responden}

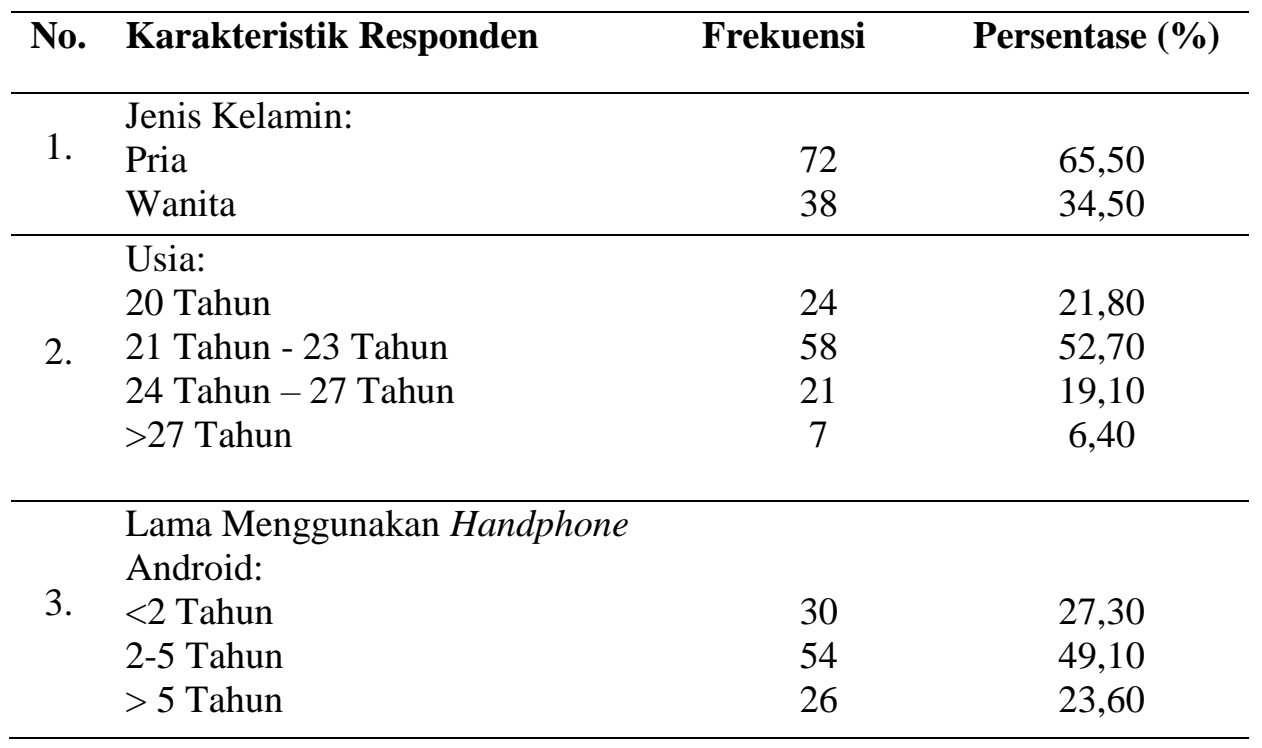

Hasil statistik dari variabel-variabel dapat dilihat pada Tabel di bawah ini :

\section{Statistik Deskriptif}

\begin{tabular}{lccc}
\hline \multicolumn{1}{c}{ Variabel } & $\mathbf{N}$ & Mean & Std. Deviation \\
\hline Brand Experience & 110 & 3,95 & 0,75 \\
\hline $\begin{array}{l}\text { Brand Relationship } \\
\text { Quality }\end{array}$ & 110 & 4,11 & 0,73 \\
\hline Brand Loyalty & 110 & 4,19 & 0,71 \\
\hline Word of Mouth & 110 & 4,07 & 0,94 \\
\hline
\end{tabular}

Nilai rata-rata yang paling tinggi dari pembentukan tanggapan terhadap Brand Loyalty diperoleh nilai rata-rata sebesar 4,19 maka menunjukkan responden setuju terhadap item-item pernyataan yang diajukan mengenai Brand Loyalty dengan standar deviasi sebesar 0,71 . Pernyataan setuju dari para responden menunjukkan bahwa saya tetap memilih handphone Android dibanding merek handphone pesaing lainnya. Hal ini menunjukkan bahwa handphone Android memiliki tampilan yang terlihat elegan sehingga pelanggan handphone Android tidak cepat bosan, handphone Android memiliki fitur yang canggih. Nilai rata-rata yang paling rendah dari pembentukan tanggapan terhadap Brand Experience diperoleh nilai rata-rata sebesar 3,95 maka menunjukkan responden cenderung setuju terhadap item-item pernyataan yang diajukan mengenai Brand Experience dengan standar deviasi sebesar 0,75 . Pernyataan cenderung setuju dari para responden menunjukkan bahwa saya menilai handphone Android dengan perasaan dan emosional. Hal ini menunjukkan bahwa handphone Android memiliki berbagai 
keunggulan dan memberikan manfaat bagi para pelanggan.

Nilai rata-rata dari pembentukan tanggapan terhadap Brand Relationship Quality diperoleh nilai rata-rata sebesar 4,11 maka menunjukkan responden setuju terhadap itemitem pernyataan yang diajukan mengenai Brand Relationship Quality dengan standar deviasi sebesar 0,73. Pernyataan setuju dari para responden menunjukkan bahwa saya memiliki komitmen terhadap handphone Android. Nilai rata-rata dari pembentukan tanggapan terhadap Word of Mouth diperoleh nilai rata-rata sebesar 4,07 maka menunjukkan responden setuju terhadap item-item pernyataan yang diajukan mengenai Word of Mouth dengan standar deviasi sebesar 0,94. Pernyataan setuju dari para responden menunjukkan bahwa saya merasa bangga ketika menggunakan handphone Android.

\section{PEMBAHASAN}

Pada Tabel diatas terlihat pada hasil pengujian tiga hipotesis penelitian bahwa Brand Experience memiliki pengaruh positif terhadap Brand Relationship Quality, Brand Relationship Quality memiliki pengaruh positif terhadap Brand Loyalty, dan Brand Loyalty memiliki pengaruh positif terhadap Word of Mouth. Adapun pembahasan dari masingmasing hipotesis penelitian sebagai berikut :

\section{Pengujian Hipotesis 1 :}

Bunyi hipotesis null $\left(\mathrm{H}_{0}\right)$ dan hipotesis alternatif $\left(\mathrm{H}_{\mathrm{a}}\right)$ adalah sebagai berikut:

$$
\begin{aligned}
\mathrm{H}_{01}: & \text { Brand Experience tidak memiliki } \\
& \text { pengaruh positif terhadap Brand } \\
& \text { Relationship Quality. }
\end{aligned}
$$

\section{$\mathrm{H}_{\mathrm{a} 1}$ : Brand Experience memiliki pengaruh positif terhadap Brand Relationship Quality.}

Pada pengujian hipotesis 1 diketahui $p$ value $0,001<$ alpha 0,05 dengan nilai beta sebesar 0,282 maka $\mathrm{H}_{1}$ didukung yang artinya Brand Experience memiliki pengaruh positif terhadap Brand Relationship Quality. Dengan adanya pengalaman afektif terhadap Handphone Android yang dimiliki oleh pengguna dapat menciptakan kualitas hubungan yang baik antara pengguna dengan Handphone Android. Hal ini ditunjukkan dengan banyaknya pengguna menilai handphone Android dengan perasaan dan emosional sehingga pengguna memiliki komitmen terhadap handphone Android.

\section{Pengujian Hipotesis 2:}

Bunyi hipotesis null $\left(\mathrm{H}_{0}\right)$ dan hipotesis alternatif $\left(\mathrm{H}_{\mathrm{a}}\right)$ adalah sebagai berikut:

$\mathrm{H}_{02}$ : Brand Relationship Quality tidak memiliki pengaruh positif terhadap Brand Loyalty.

$\mathrm{H}_{\mathrm{a} 2}$ : Brand Relationship Quality memiliki pengaruh positif terhadap Brand Loyalty. Pada pengujian hipotesis 2 diketahui $p$ value $0,008<$ alpha 0,05 dengan nilai beta sebesar 0,304 maka $\mathrm{H}_{2}$ didukung yang artinya Brand Relationship Quality memiliki pengaruh positif terhadap Brand Loyalty. Dengan terbentuknya hubungan yang baik antara pengguna dengan Handphone Android dapat menciptakan kedalaman komitmen untuk tetap membeli handphone Android dari dalam diri pengguna. Hal ini ditunjukkan dengan peneliti berusaha untuk tetap memilih handphone Android sehingga tetap memilih handphone Android dibanding merek handphone pesaing lainnya.

\section{Pengujian Hipotesis 3:}

Bunyi hipotesis null $\left(\mathrm{H}_{0}\right)$ dan hipotesis alternatif $\left(\mathrm{H}_{\mathrm{a}}\right)$ adalah sebagai berikut:

$\mathrm{H}_{03}$ : Brand Loyalty tidak memiliki pengaruh positif terhadap Word of Mouth.

$\mathrm{H}_{\mathrm{a} 3}$ : Brand Loyalty memiliki pengaruh positif terhadap Word of Mouth.

Pada pengujian hipotesis 3 diketahui $p$ value $0,004<$ alpha 0,05 dengan nilai beta sebesar 0,383 maka $\mathrm{H}_{3}$ didukung, yang artinya Brand Loyalty memiliki pengaruh positif terhadap Word of Mouth. Dengan adanya keinginan untuk tetap membeli handphone Android dari pengguna dapat menciptakan pemberian rekomendasi kepada pelanggan lainnya yang ingin membeli handphone Android. Hal ini ditunjukkan dengan peneliti menyukai handphone Android karena manfaat dan kegunaannya sehingga Handphone Android membuat penggunannya senang.

Hipotesis Satu: Brand Experience memiliki pengaruh positif terhadap Brand Relationship Quality. 
Pengalaman emosional yang dimiliki oleh pengguna dapat menjadikannya lebih mengetahui perbedaan antara handphone Android dengan handphone merek pesaing lainnya. Keunggulan handphone android lain yang sangat power full adalah performance yang luar biasa dan dapat digunakan secara multitasking atau menjalankan beberapa aplikasi secara bersamaan. Fitur-fitur unggulan yang ada di android adanya aplikasi yang sangat beragam ribuan aplikasi tersedia di Google Play Store, kembali ke point pertama karena open source banyak developer I pengembang aplikasi yang membuat aplikasi, tidak terkecuali anda bila berminat. Sehingga aplikasi pun bisa di upgrade secara up to date dan tentu semakin berkualitas. Fitur seperti rincian cuaca, membuka layar, RSS feed, Twitter, Facebook, dll. Ketersediaan aplikasi BB (Blackberry) versi android serta aplikasi iPhone yang versi Android juga bisa anda dapatkan. Dengan kelebihan dan fitur lengkap dari handphone Android membuat pengguna menjalin hubungan baik dengan perusahaan yang menjual handphone Android.

Dimana hasil uji hipotesis yang diperoleh pada pengaruh positif Brand Experience terhadap Brand Relationship Quality diperoleh nilai beta sebesar 0,282 dan nilai signifikan sebesar $0,001 \quad(\beta=0,282$ dan $p$ value $<0,05)$. Dengan adanya pengaruh positif Brand Experience terhadap Brand Relationship Quality menunjukkan bahwa dengan adanya pengalaman afektif yang baik dimiliki oleh pengguna dapat menciptakan kualitas hubungan yang baik antara pengguna dengan handphone Android. Hasil penelitian ini mendukung hasil penelitian yang dilakukan oleh Lee dan Kang (2012). Di dalam penelitian Lee dan Kang (2012) ditunjukkan bahwa besarnya pengaruh positif Brand Experience terhadap Brand Relationship Quality diperoleh nilai beta sebesar 0,674 dan nilai signifikan sebesar 0,000 .

\section{Hipotesis Dua: Brand Relationship Quality memiliki pengaruh positif terhadap Brand Loyalty.}

Keinginan pengguna menjalin hubungan dengan handphone Android karena handphone Android telah merasakan keunggulan dari handphone Android yang mampu membuka beberapa aplikasi sekaligus tanpa harus menutup salah satunya. Kalau anda seneng install aplikasi ataupun games, lewat Google Android Application Market Anda bisa mendownload berbagai aplikasi dengan gratis. Ada banyak ribuan aplikasi dan games yang siap untuk anda download di ponsel Android. Handphone Android terlihat stabil dan tidak mudah error. Keinginan menjalin hubungan dengan handphone Android dari pengguna membuat pengguna ingin membeli handphone Android di masa yang akan datang.

Dimana hasil uji hipotesis yang diperoleh pada pengaruh positif Brand Relationship Quality terhadap Brand Loyalty diperoleh nilai beta sebesar 0,304 dan nilai signifikan sebesar $0,008 \quad(\beta=0,304$ dan $p$ value $<0,05$ ). Dengan adanya pengaruh positif Brand Relationship Quality terhadap Brand Loyalty menunjukkan bahwa dengan adanya pembentukan kualitas hubungan baik antara pelanggan dengan handphone Android dapat menciptakan kedalaman komitmen untuk tetap menggunakan handphone Android. Hasil penelitian ini mendukung hasil penelitian yang dilakukan oleh Lee dan Kang (2012). Di dalam penelitian Lee dan Kang (2012) ditunjukkan bahwa besarnya pengaruh positif Brand Relationship Quality terhadap Brand Loyalty diperoleh nilai beta sebesar 0,499 dan nilai signifikan sebesar 0,000 .

\section{Hipotesis Tiga: Brand Loyalty memiliki pengaruh positif terhadap Word of Mouth.}

Loyalitas merek merupakan satu ukuran keterkaitan seseorang pelanggan pada sebuah merek. Apabila loyalitas merek meningkat, maka kerentaan kelompok pelanggan dari serangan kompetitor dapat dikurangi. Loyalitas merek dan para pelanggan yang ada mewakili suatu strategic asset yang jika dikelola dengan benar, mempunyai potensi untuk memberikan nilai bagi perusahaan. Loyalitas merek menunjukkan sebagai suatu ukuran keterkaitan pelanggan kepada sebuah merek. Ukuran ini mampu memberikan gambaran tentang mungkin tidaknya seorang pelanggan beralih ke merek lain yang ditawarkan oleh kompetitor, terutama jika pada merek tersebut didapati adanya perubahan, baik menyangkut harga ataupun atribut lainnya. Seorang pelanggan yang sangat loyal kepada suatu merek tidak akan dengan mudah memindahkan pembeliannya ke merek lain, apa pun yang terjadi dengan merek tersebut. Apabila loyalitas 
pelanggan terhadap suatu merek meningkat, kerentanan kelompok pelanggan tersebut dari ancaman dan serangan merek produk pesaing dapat dikurangi. Dengan kedalaman komitmen untuk tetap membeli handphone Android dapat menciptakan pemberian informasi positif dari dalam diri pelanggan kepada pelanggan lainnya. Pemberian rekomendasi berarti adanya komunikasi yang dilakukan melalui pembicaraan dari mulut ke mulut dengan cara menceritakan pengalaman atau keunggulan produk atau jasa.

Dimana hasil uji hipotesis yang diperoleh pada pengaruh positif Brand Loyalty terhadap Word of Mouth diperoleh nilai beta sebesar 0,383 dan nilai signifikan sebesar 0,004 ( $\beta=0,383$ dan $p$-value $<0,05)$. Dengan adanya pengaruh positif Brand Loyalty terhadap Word of Mouth menunjukkan bahwa dengan keinginan untuk tetap membeli handphone Android dari dalam diri pengguna dapat menciptakan keinginan memberikan informasi manfaat yang diperoleh kepada orang lain seperti teman, keluarga, dan rekan kerja. Hasil penelitian ini mendukung hasil penelitian yang dilakukan oleh Gounaris dan Stathakopoulos (2004). Di dalam penelitian Gounaris dan Stathakopoulos (2004) ditunjukkan bahwa besarnya pengaruh positif Brand Loyalty terhadap Word of Mouth diperoleh nilai beta sebesar 0,320 dan nilai signifikan sebesar 0,001 .

\section{SIMPULAN DAN SARAN}

Berdasarkan uraian dan analisis yang telah dikemukakan, maka kesimpulan dari penelitian ini adalah Brand Loyalty mempengaruhi Word of Mouth karena dengan kedalaman komitmen yang dimiliki oleh para pelanggan handphone Android memiliki dampak terhadap timbulnya pemberian informasi dari seorang pelanggan mengenai keunggulan dari handphone Android terhadap pelanggan lainnya. Hal ini ditunjukkan dengan masyarakat menyukai handphone Android karena manfaat dan kegunaannya sehingga Handphone Android membuat penggunanya senang.

Delgado-Ballester (2004) menyatakan bahwa kepercayaan pelanggan terhadap merek produk atau jasa merupakan suatu tujuan dalam pemasaran melalui pembentukan hubungan antara pelanggan dengan merek produk atau layanan jasa, sehingga pelanggan selalu menggunakan merek produk atau jasa tersebut. Mukherjee dan Nath (2007) berpendapat mengenai the commitment-trust theory (CTT) berhubungan dengan relationship marketing pada konteks retail yang menggunakan internet. mengenai the commitment-trust theory (CTT) bahwa kepercayaan dan komitmen berhubungan dengan faktor yang menentukan dalam membentuk dan mempertahankan keberhasilan dalam suatu proses pemasaran. Dan teori the commitment-trust theory (CTT) menyatakan bahwa kepercayaan dan komitmen berkaitan erat dalam hubungan pemasaran yang digunakan oleh para pemasar untuk bekerja sama dengan pihak lain, mencari berbagai alternatif dalam jangka pendek dengan bekerja sama antara pihak yang terlibat dalam jangka panjang, melihat resiko karena dengan kerja sama resiko itu dapat dihindari. agar produk handphone Android selalu dapat diterima masyarakat dengan baik, maka produsen tidak hanya memperhatikan kualitas yang baik saja tapi juga harus dapat mempertimbangkan aspek lain seperti yang telah disebutkan diatas. Berdasarkan kesimpulan penelitian maka saran untuk peneliti selanjutnya dengan memperbaiki kekurangan ataupun keterbatasan yang ada dalam penelitian ini yaitu :

1. Peneliti selanjutnya sebaiknya tidak hanya melakukan penelitian pada orang yang membeli handphone Android sebagai responden, tapi juga harus memperhatikan perkembangan teknologi terbaru.

2. Dengan menambah responden yang membeli handphone Android sebagai responden agar penelitian yang dilakukan lebih valid dan akurat serta mewakili jumlah populasi yang ada.

3. Meneliti variabel lainnya seperti sesuai yang disarankan pada jurnal penelitian yang dilakukan Lee dan Kang (2012).

\section{DAFTAR RUJUKAN}

Delgado-Ballester, E. (2004) "Applicability of a brand trust scale across product categories: A multigroup invariance analysis", European Journal of Marketing, Vol. 38 Iss: 5/6, pp.573-592. 
Fullerton, G. (2005), "The Impact of Brand Commitment on Loyalty to Retail Service Brands", Canadian Journal of Administrative Sciences; Jun 2005; 22, 2; ABI/INFORM Complete, pp. 97.

Gounaris, Spiros and Stathakopoulos, Vlasis (2004), Antecedents And Consequences of Brand Loyalty: An Empirical Study, Journal of Brand Management, 11, 4; 283-306.

Hermawan, A. (2006), Penelitian Bisnis Paradigma Kuantitatif, Jakarta : Grasindo.

Joy, A. and Jr.J.F. Sherry (2003), "Speaking of art as embodied imagination: A multisensory approach to understanding aesthetic experience", Journal of Consumer Research, 20 (September), pp.259-82.

Lee, H.J. and Soo, K.M. (2012), "The Effect Of Brand Experience On Brand Relationship Quality", Academy of Marketing Studies Journal, 16. 1 (2012): 87-98.

Lee, H.J. and Kang, M.S. (2012), "The Effect of Brand Experience on Brand Relationship Quality", Academy of Marketing Studies Journal, Volume 16, Number 1, pp. 1-13.

Louis, D. and Lombart, C. (2010), "Impact of brand personality on three major relational consequences (trust, attachment, and commitment to the brand)", Journal of Product \& Brand Management, Vol.19/ No.2, pp. 114130.

Moisescu, Ovidiu. I. and Allen, Brad. (2010), "The Relationship between the dimensions of brand loyalty. an empirical investigation among romanian urban consumers", Management \& Marketing, 5, 4, pp. 83-98.

Mukherjee, A. and Nath, P. (2007), "Role of electronic trust in online retailing: A reexamination of the commitment-trust theory", European Journal of Marketing, 41 (9/10), pp. 1173-1202.

Xie, D.D.H. and V.C.S. Heung (2009), "The effects of brand relationship quality on hotel consumers' responses to service failure", International Journal of Business Research, 10(4), pp. 120-125.

Youl-Ha, H., John, J., Janda, S., and Muthaly, S. (2011), "The effects of advertising spending on brand loyalty in services", European Journal of Marketing, Vol. 45 No. 4, pp. 673-691.

Zarantonello, L. and Schmitt, B.H. (2010), "Using the brand experience scale to profile consumers and predict consumer behaviour", Brand Management, Vol. 17, 7, 532-540. 